\title{
Virus en Endodoncia
}

\author{
Viruses in Endodontics
}

\begin{abstract}
Scarlette Hernández Vigueras*; Luis Salazar Navarrete**; Ricardo Pérez Tomás ${ }^{* * *}$; Juan José Segura Egea ${ }^{* * * *} ;$ Miguel Viñas $^{\star * * *}$ \& José López-López ${ }^{* * * * *}$
\end{abstract}

HERNÁNDEZ-VIGUERAS, S.; SALAZAR, N. L.; PÉREZ-TOMÁS R.; SEGURA-EGEA, J. J; VIÑAS, M.; LÓPEZ-LÓPEZ, J. Virus en Endodoncia. Int. J. Odontostomat., 8(2):211-214, 2014.

RESUMEN: La infección endodóntica es la infección que afecta al sistema de conductos radiculares y, sin duda, es el principal agente etiológico de las periodontitis apicales. Además, de las bacterias patógenas endodónticas, se ha buscado en los últimos años asociar la presencia de virus en distintos tipos de patología endodóntica. Los virus que más se han buscado y asociado son los pertenecientes a la familia herpesvirus, los cuales se han encontrado presentes en patologías periapicales principalmente. Se ha buscado además, relacionar su presencia a patologías que cursan con mayor sintomatología, o que presentan a la imagen radiográfica destrucciones óseas periapicales mayores. El rol de los virus en las lesiones apicales de origen endodóntico está aún poco claro, se habla de efectos acumulativos a los de las bacterias, además de posibles inmunosupresiones locales que favorecerían el crecimiento y el efecto de estas últimas.

PALABRAS CLAVE: Herpesvirus, virus papiloma humano, citomegalovirus, virus Epstein-Barr, periodontitis apical, infección endodóntica, endodoncia.

\section{INTRODUCCIÓN}

La infección endodóntica se define como la infección que afecta al sistema de conductos radiculares $y$, sin duda, es el principal agente etiológico de las periodontitis apicales. Factores químicos y físicos pueden inducir inflamación periapical, pero el factor microbiológico es esencial para que esta inflamación pueda persistir y progresar (Siqueira \& Rocas, 2009).

Las periodontitis apicales o lesiones periapicales, es la enfermedad inflamatoria que afecta a los tejidos circundantes de la porción apical del diente, causando la destrucción de estos tejidos (Graunaite et al., 2012; Siqueira \& Rocas). Estas infecciones polimicrobianas pueden presentar un curso agudo o crónico, y tener diversas manifestaciones o características clínicas y radiográficas. El tipo de respuesta o variación en sus características clínicas pueden deberse a los diferentes perfiles microbiológicos que se presenten, o a la respuesta inmunitaria del huésped (Slots et al., 2004).

En la actualidad, se utiliza la clasificación consenso de la Asociación Americana de Endodoncia (Glickman, 2009), que al hablar de las periodontitis apicales, distingue: i) Las sintomáticas, que pueden ir o no acompañadas de un área radiolúcida periapical. ii) Las asintomáticas las cuales, que aparecen como un área radiolúcida periapical, pero no se acompaña de ninguna sintomatología clínica.

\footnotetext{
Facultad de Medicina, Universidad Austral de Chile, Valdivia, Chile. Doctorado Ciencias Odontológicas, Campus Universitario de Bellvitge, Universidad de Barcelona, España.

* Laboratorio de Biología Molecular y Farmacogenética, Departamento de Ciencias Básicas, Facultad de Medicina, Universidad de La Frontera, Temuco, Chile.

*** Full Professor. Departamento de Ciencias Básicas. Campus Universitario de Bellvitge. Universidad de Barcelona, España.

***** Full Professor. Departamento de Estomatología. Universidad de Sevilla, Sevilla, España.

*at** Laboratory of Molecular Microbiology and Antimicrobials. Department of Pathology and Experimental Therapeutics, University of Barcelona, España.

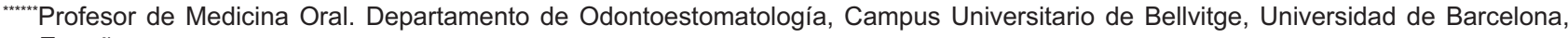
España.

Fondos de la Dirección de Investigación y Desarrollo, Universidad Austral de Chile, Chile, Proyecto DID S-2012-05.
} 
El impacto de las periodontitis apicales no es sólo a nivel de cavidad oral, sino también en su posible relación con diversas patologías o condiciones sistémicas como diabetes tipo 2 (López-López et al., 2011) o tabaco e hipertensión (Segura-Egea et al., 2011), entre otras entidades.

Más de 500 especies de microorganismos colonizan la cavidad oral, pero sólo de 15 a 30 son las que se detectan con frecuencia en los canales infectados, pudiendo ser las responsables de la mayoría de las periodontitis apicales en individuos inmunológicamente competentes. Otro número menor de especies pueden verse involucradas en otro tipo de casos, particularmente en los casos de fracasos post endodoncia (Siqueira \& Rocas).

Los virus son agentes ulcerogénicos y cancerogénicos en la cavidad oral y su infectación es frecuente en la mucosa y zona perioral. Las patologías orales que se relacionan con agentes virales, son úlceras orales, tumores y otras patologías como la periodontitis marginal y liquen plano entre otras. Por esto, en los últimos años se ha buscado relacionar diversos virus, además de las bacterias específicas, con periodontitis apicales sintomáticas y asintomáticas, utilizando para su detección técnicas de inmunohistoquímica y la detección en cadena de la polimerasa (PCR) (Li et al., 2009; Sabeti et al., 2003; Saboia-Dantas et al., 2007).

En los últimos años, la atención de los estudios se ha centrado en la detección de virus de la familia herpesvirus. Particularmente, los estudios se enfocan en el virus Epstein Barr o VHS-4 (VEB), Citomegalovirus o VHS-5(CV) y Herpes simplex (VHS 1 y 2). Sin embargo, Ferreira et al. (2011), buscaron y detectaron en muestras de exudado purulento de abscesos apicales agudos, la presencia de otros virus pertenecientes a la familia herpesvirus, como el VHS6 , VHS-8, además de buscar y detectar la presencia del virus papiloma humano.

Virus asociados a patologías endodónticas. Los herpesvirus o virus pertenecientes a la familia herpesviridae, son una de las mayores familias virales presentes en la cavidad oral. Son virus DNA (doble cadena lineal) y el tamaño del virión de herpesvirus varía de 120-150 nm. Presentan una cápside icosaédrica, tegumento proteináceo y una envoltura con glicoproteínas virales. Se conocen 8 tipos de especies de herpesvirus humano: Herpes simplex 1 (HSV-1), Herpes simplex 2 (HSV-2), Varicela-zóster
(VZV) o herpes virus 3, Epstein-Barr (EBV) o herpes virus 4 , Citomegalovirus (CMV) o herpes virus 5 , Herpes virus 6 (HHV-6), 7 (HHV-7) y 8 (HHV-8). Cada uno de estos virus difiere en características biológicas y clínicas (Slots, 2009).

EI HSV-1 y 2 se ha buscado en diversos estudios, sin embargo, en ninguno se presenta con una diferencia estadísticamente significativa, se presentan casos aislados, lo que parece indicar que estos virus no estarían asociados a un potencial rol en las enfermedades endodónticas (Chen et al., 2009; Ferreira et al.; Heling et al., 2001; Li et al.; Rosaline et al., 2009; Sabeti et al., 2003a; Sabeti et al., 2003b; Sabeti \& Slots, 2004; Sabeti et al. 2003c).

A su vez, el VZV se ha buscado en tres estudios, en los que aparece presente en un número muy bajo de muestras, incluso un caso en que aparecía presente, se asoció finalmente a un diagnóstico errado de herpes zóster, el cual presentó sintomatología similar a una pulpitis irreversible sintomática (Chen et al.; Ferreira et al.; Li et al.). El HHV-4 o EBV es uno de los que más se ha asociado en estudios a patología endodóntica, encontrándose presente en un significativo número de muestras en comparación con grupos control sanos (Chen et al.; Ferreira et al.; Hernádi et al., 2010; Li et al.; Ozbek et al., 2013; Rosaline et al.; Sabeti et al., 2012; Sabeti et al., 2003a, 2003b, 2003c; Sabeti \& Slots, 2004; Saboia-Dantas et al.; Slots et al.; Sunde et al., 2008; Yazdi et al., 2008; Yildirim et al., 2006).

El HHV-5 o Citomegalovirus (CMV) también, junto al EBV es uno de los más estudiados (Andric et al., 2007; Chen et al.; Ferreira et al.; Hernádi et al., 2010; Li et al.; Ozbek et al.; Rosaline et al.,; Sabeti et al., 2012; Sabeti et al., 2003a, 2003b, 2003c; Sabeti \& Slots, 2004; Saboia-Dantas et al. Slots et al.; Sunde et al.; Yazdi et al.; Yildirim et al.); sin embargo, en estudios en los que aparece presente en muestras con patología endodóntica no hay diferencia estadísticamente significativa con los grupos controles (Hernádi et al., 2010; Li et al.), por lo que su potencial rol en la patología endodóntica, es controvertido. La principal asociación viral encontrada en los estudios fue la de CMV y EBV, presente en casi un tercio de las muestras con patología endodóntica estudiada (Hernádi et al., 2010; Li et al.; Ozbek et al.; Sabeti et al., 2012; Sabeti et al., 2003a, 2003b, 2003c; Sabeti \& Slots, 2004; Saboia-Dantas et al. Slots et al.; Sunde et al.; Yazdi et al.; Yildirim et al.). En dientes temporales con patología periapical también se 
ha evaluado la presencia de estos virus en un total de 12 muestras, estando presente el EBV en 8 y el CMV en 7, diferencia estadísticamente significativa al ser comparada con el grupo control (premolares sanos extraídos por motivos ortodóncicos) (Yildirim et al.).

Con respecto a la detección del HHV-6, existen dos estudios que han buscado este virus. Hernádi et al. (2011), lo detectó en 8 de 40 muestras de lesiones periapicales, y Ferreira et al. detectaron su presencia en 2 de 33 muestras de abscesos apicales agudos. Ferreira et al., además, estudiaron la presencia de HHV-7 y HHV-8 en abscesos apicales agudos, encontrando HHV-7 en sólo una muestra de abscesos apicales y en una control, en cambio, albuscar el HHV-8, encontró que en 18 de las 33 muestras de abscesos, el virus aparecía presente. La presencia de este virus se asocia fuertemente a población $\mathrm{VIH}(+)$, sin embargo, de los pacientes del estudio, ninguno era portador del VIH (Ferreira et al.).

EI HPV, pertenece a la familia papillomaviridae, es un virus de doble cadena de DNA, circular, del cual se han identificado más de 120 tipos. Es un virus pequeño, tiene tropismo epitelial y no presenta envoltura. En los humanos se han asociado a una variedad de lesiones epiteliales proliferativas, incluso se ha asociado a condiciones premalignas o malignas (Kumaraswamy \& Vidhya, 2011). No obstante se han encontrado pocos estudios que detecten su presencia asociado a patología endodóntica, el más reciente, lo asocia a abscesos apicales agudos (Ferreira et al.), resultando positivo en 3 de las 33 muestras de exudado purulento.

Virus y su relación con la sintomatología y el tamaño de las lesiones apicales radiculares. Se ha buscado correlacionar la presencia de agentes virales específicos con patología endodóntica que cursa con sintomatología como tumefacción, dolor, sensibilidad al morder, a la palpación o a la percusión. Los virus que han aparecidos asociados a este tipo de lesiones son el virus de Epstein-Barr y el Citomegalovirus, solos o asociados (Sabeti et al., 2003c, 2012; Sabeti \& Slots; Slots et al.). Sin embargo, en otros estudios no se ha encontrado ninguna relación estadísticamente significativa al comparar la presencia viral entre periodontitis apicales sintomáticas y asintomáticas (Andric et al.; Hernádi et al., 2010; Li et al.; Ozbek et al.).

En relación a la presencia de virus según el tamaño de la lesión apical, los resultados difieren. Sabeti et al. (2003a), Sabeti \& Slots y Hernádi et al. $(2010,2011)$ encuentraron una relación entre la presencia de virus EBV, CMV y HHV-6 subtipo B en lesiones apicales de gran tamaño. Por el contrario $\mathrm{Li}$ et al. no encuentra diferencia estadísticamente significativa.

En la actualidad, falta describir el rol de los virus en las lesiones periapicales, postulándose posibles efectos acumulativos de la presencia de virus, más bacterias endopatógenas y la activación de mecanismos inmunes proinflamatorios que pueden manifestarse en un aumento de la reabsorción periapical y en síntomas clínicos. La presencia del virus puede causar una inmunosupresión local, que favorezca el crecimiento bacteriano en el periápice. Por otro lado los virus pueden estar presentes y replicarse en el ser humano, pero sin causar síntomas, por esto se debe ser cuidadoso al considerar la relevancia clínica de la presencia viral. Es importante el conocer y entender las nuevas interacciones microbiológicas que se producen en las patologías endodónticas, las cuales podrían dar luces para nuevos enfoques terapéuticos, buscando mejorar el pronóstico de las terapias.

HERNÁNDEZ-VIGUERAS, S.; SALAZAR, N. L.; PÉREZ-TOMÁS R.; SEGURA-EGEA, J. J; VIÑAS, M.; LÓPEZ-LÓPEZ, J. Viruses in endodontics. Int. J. Odontostomat., 8(2):211-214, 2014.

ABSTRACT: Endodontic infection is an infection of the root canal system and undoubtedly is the main etiological agent of apical periodontitis. In recent years, research has aimed to associate the presence of virus and endodontic bacterial pathogens in the different types of endodontic disease. The most common viruses that have been researched and associated are members of the herpesvirus family, which are mainly present in periapical pathologies. Furthermore, research has been carried out relating their presence to pathologies with important symptoms, or those where radiographic imaging shows extensive apical bone reabsorption. The role of viruses in apical lesions of endodontic origin are still unclear, it hypothesizes the cumulative effect with bacteria, in addition to possible local immunosuppression that favors the growth and the effect of bacteria.

KEY WORDS: Herpes virus, human papillomavirus, human cytomegalovirus, Epstein-barr virus, apical periodontitis, endodontic infection, endodontic. 


\section{REFERENCIAS BIBLIOGRÁFICAS}

Andric, M.; Milasin, J.; Jovanovic, T. \& Todorovic, L. Human cytomegalovirus is present in odontogenic cysts. Oral Microbiol. Immunol., 22(5):347-51, 2007.

Chen, V.; Chen, Y.; Li, H.; Kent, K.; Baumgartner, J. C. \& Machida, C. A. Herpesviruses in abscesses and cellulitis of endodontic origin. $J$. Endod., 35(2):182-8, 2009.

Ferreira, D. C.; Rôças, I. N.; Paiva, S. S.; Carmo, F. L.; Cavalcante, F. S.; Rosado, A. S.; Santos, K. R. \& Siqueira, J. F. Jr. Viral-bacterial associations in acute apical abscesses. Oral Surg. Oral Med. Oral Pathol. Oral Radiol. Endod., 112(2):264-71, 2011.

Glickman, G. N. AAE Consensus Conference on Diagnostic Terminology: background and perspectives. J. Endod., 35(12):1619-20, 2009.

Graunaite, I.; Lodiene, G. \& Maciulskiene, V. Pathogenesis of apical periodontitis: a literature review. J. Oral Maxillofac. Res., 2(4):e1, 2012.

Heling, I.; Morag-Hezroni, M.; Marva, E.; Hochman, N.; Zakay-Rones, Z. \& Morag, A. Is herpes simplex virus associated with pulp/ periapical inflammation? Oral Surg. Oral Med. Oral Pathol. Oral Radiol. Endod., 91(3):359-61, 2001.

Hernádi, K.; Csoma, E.; Adám, B.; Szalmás, A.; Gyöngyösi, E.; Veress, G.; Ildikó-Márton, I. \& Kónya, J. Association of human herpesvirus 6 subtypes with symptomatic apical periodontitis. Oral Surg. Oral Med. Oral Pathol. Oral Radiol. Endod., 112(3):401-6, 2011.

Hernádi, K.; Szalmás, A.; Mogyorósi, R.; Czompa, L.; Veress, G.; Csoma, E.; Martón, I. \& Kónya, J. PrPrevalence and activity of EpsteinBarr virus and human cytomegalovirus in symptomatic and asymptomatic apical periodontitis lesions. J. Endod., 36(9):14859, 2010.

Kumaraswamy, K. L. \& Vidhya, M. Human papilloma virus and oral infections: an update. J. Cancer Res. Ther., 7(2):120-7, 2011.

Li, H.; Chen, V.; Chen, Y.; Baumgartner, J. C. \& Machida, C. A. Herpesviruses in endodontic pathoses: association of Epstein-Barr virus with irreversible pulpitis and apical periodontitis. J. Endod., 35(1):23-9, 2009.

López-López, J.; Jané-Salas, E.; Estrugo-Devesa, A.; Velasco-Ortega, E.; Martín-González, J. \& Segura-Egea, J. J. Periapical and endodontic status of type 2 diabetic patients in Catalonia, Spain: a cross-sectional study. J. Endod., 37(5):598-601, 2011.

Ozbek, S. M.; Ozbek, A. \& Yavuz, M. S. Detection of human cytomegalovirus and Epstein-Barr Virus in symptomatic and asymptomatic apical periodontitis lesions by real-time PCR. Med. Oral Patol. Oral Cir. Bucal, 18(5):e811-6, 2013.

Rosaline, H.; Satish, E. S. \& Kandaswamy, D. Detection of presence or absence of herpes simplex virus, Epstein Barr virus and human cytomegalovirus in infected pulp using a polymerase chain reaction. Aust. Endod. J., 35(1):9-12, 2009.

Sabeti, M.; Kermani, V.; Sabeti, S. \& Simon, J. H. Significance of human cytomegalovirus and Epstein-Barr virus in inducing cytokine expression in periapical lesions. J. Endod., 38(1):47-50, 2012.
Sabeti, M.; Simon, J. H.; Nowzari, H. \& Slots, J. Cytomegalovirus and Epstein-Barr virus active infection in periapical lesions of teeth with intact crowns. J. Endod., 29(5):321-3, $2003 a$.

Sabeti, M.; Simon, J. H. \& Slots, J. Cytomegalovirus and Epstein-Barr virus are associated with symptomatic periapical pathosis. Oral Microbiol. Immunol., 18(5):327-8, 2003b.

Sabeti, M. \& Slots, J. Herpesviral-bacterial coinfection in periapical pathosis. J. Endod., 30(2):69-72, 2004.

Sabeti, M.; Valles, Y.; Nowzari, H.; Simon, J. H.; Kermani-Arab, V. \& Slots, J. Cytomegalovirus and Epstein-Barr virus DNA transcription in endodontic symptomatic lesions. Oral Microbiol. Immunol., 18(2):104-8, 2003c

Saboia-Dantas, C. J.; Coutrin de Toledo, L. F.; Sampaio-Filho, H. R. \& Siqueira, J. F. Jr. Herpesviruses in asymptomatic apical periodontitis lesions: an immunohistochemical approach. Oral Microbiol. Immunol., 22(5):320-5, 2007.

Segura-Egea, J. J.; Castellanos-Cosano, L.; Velasco-Ortega, E.; RíosSantos, J. V.; Llamas-Carreras, J. M.; Machuca, G. \& López-Frías, F. J. Relationship between smoking and endodontic variables in hypertensive patients. J. Endod., 37(6):764-7, 2011.

Siqueira, J. F. Jr. \& Rôças, I. N. Distinctive features of the microbiota associated with different forms of apical periodontitis. J. Oral Microbiol., 1:10.3402/jom.v1i0.2009, 2009.

Slots, J. Oral viral infections of adults. Periodontol. 2000, 49:60-86, 2009.

Slots, J.; Nowzari, H. \& Sabeti, M. Cytomegalovirus infection in symptomatic periapical pathosis. Int. Endod. J., 37(8):519-24, 2004.

Sunde, P. T.; Olsen, I.; Enersen, M.; Beiske, K. \& Grinde, B. Human cytomegalovirus and Epstein-Barr virus in apical and marginal periodontitis: a role in pathology? J. Med. Virol., 80(6):1007-11, 2008.

Yazdi, K. A.; Sabeti, M.; Jabalameli, F.; Eman eini, M.; Kolahdouzan, S. A. \& Slots, J. Relationship between human cytomegalovirus transcription and symptomatic apical periodontitis in Iran. Oral Microbiol. Immunol., 23(6):510-4, 2008.

Yildirim, S.; Yapar, M.; Kubar, A. \& Slots, J. Human cytomegalovirus, Epstein-Barr virus and bone resorption-inducing cytokines in periapical lesions of deciduous teeth. Oral Microbiol. Immunol., 21(2):107-11, 2006.

Dirección para Correspondencia:

Scarlette Hernández Vigueras Instituto de Odontoestomatología

Universidad Austral de Chile

Rudloff 1640, Valdivia

CHILE

Email: shernandez@uach.cl

Recibido : 27-03-2014

Aceptado: 23-07-2014 